\title{
Ab interno canaloplasty for the treatment of glaucoma: a case series study
}

\author{
Norbert Körber
}

Received: 16 August 2016 / Accepted: 16 October 2018 / Published online: 31 October 2018

(C) The Author(s) 2018

\begin{abstract}
Summary
Purpose To describe and evaluate the efficacy of ab interno canaloplasty $(\mathrm{ABiC})$ in patients with primary open-angle glaucoma (POAG).

Methods This single-center consecutive case series study included patients with cataract and open-angle glaucoma (combined procedure) and pseudophakic patients (mean age, 76 years; range, 66-83 years) with POAG who underwent $\mathrm{ABiC}$ using the iTrack ${ }^{\mathrm{TM}}$ 250$\mu \mathrm{m}$ microcatheter (Ellex Medical Lasers Pty Ltd, Adelaide, Australia) to circumferentially viscodilate and intubate Schlemm's canal without placement of a tensioning suture. The primary endpoints were mean intraocular pressure (IOP) and mean number of glaucoma medications at $1,3,6,9$, and 12 months postoperatively.

Results In total, 20 patients (20 eyes) were enrolled in the study. Mean IOP reduced from $18.5 \pm 3.44 \mathrm{~mm} \mathrm{Hg}$ preoperatively to $14.88 \pm 2.82 \mathrm{mmHg}(n=17), 13.80 \pm$ $2.05(n=12), 14.57 \pm 2.59 \mathrm{~mm} \mathrm{Hg}(n=9)$ and $15.47 \pm 2.42$ $(n=6)$ at $1,3,6$ and 9 months postoperatively. The 12-month data for two patients showed that IOP had reduced from $17 \mathrm{~mm} \mathrm{Hg}$ preoperatively to $16 \mathrm{~mm} \mathrm{Hg}$ in one patient and from $20 \mathrm{~mm} \mathrm{Hg}$ to $13 \mathrm{~mm} \mathrm{Hg}$ in the other patient. The mean number of medications was reduced from 2.4 preoperatively to 0.25 at the last follow-up visit. There was one reported complication of limited descemetolysis near the limbus by the viscoelastic during the dilatation of Schlemm's canal. No adverse events as a result of the device were reported. Conclusions ABiC was straightforward to perform in this group of patients with minimal complications. Although initial findings from this study indicate that
\end{abstract}

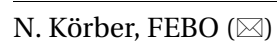

Augencentrum Köln-Porz, Josefstraße 14, 51143 Cologne, Germany

N.Koerber@gmx.de
$\mathrm{ABiC}$ is comparable to conventional canaloplasty in lowering IOP and medication dependency, long-term follow-up in a large patient cohort is required to confirm the efficacy of this minimally invasive glaucoma procedure.

Keywords Canaloplasty $\cdot \mathrm{ABiC} \cdot \mathrm{Combined}$ operation . POAG

\section{Ab-Interno Kanaloplastik zur Behandlung des Glaukoms: eine Fallseriestudie}

\section{Zusammenfassung}

Zweck Die Wirksamkeit und die Durchführung der Kanaloplastik ab interno (ABiC) bei Patienten mit primärem Offenwinkelglaukom werden beschrieben.

Methodik Diese konsekutive Einzelzentrum-Fallstudie schließt Patienten mit Katarakt und Offenwinkelglaukom (kombinierte Operation) und Patienten mit Pseudophakie und Offenwinkelglaukom (POAG) ein, bei denen eine $\mathrm{ABiC}$ mit dem iTrack ${ }^{\mathrm{TM}} 250-\mu \mathrm{m}-\mathrm{Mi}-$ krokatheter (Fa. Ellex Medical Lasers Pty Ltd, Adelaide, Australien) durchgeführt wurde, um so den SchlemmKanal zirkulär $\mathrm{zu}$ viskodilatieren und $\mathrm{zu}$ sondieren, ohne eine Spannnaht zu implantieren (mittleres Alter: 76 Jahre, Spannbreite: 66-83 Jahre). Die primären Endpunkte waren der Intraokulardruck (IOP) und die mittlere Zahl von Glaukommedikamenten 1, 3, 6, 9 und 12 Monate postoperativ.

Ergebnisse Zwanzig Patienten (20 Augen) wurden in die Studie eingeschlossen. Der mittlere IOP wurde von $18,5 \pm 3,44$ präoperativ auf $14,88 \pm 2,82 \mathrm{mmHg}$ $(n=17), 13,80 \pm 2,05 \quad(n=12), 14,57 \pm 2,59 \mathrm{mmHg}$ und $15,47 \pm 2,42(n=6)$ nach $1,3,6$ und 9 Monaten postoperativ reduziert. Die 12-Monats-Daten für 2 Patienten ergaben eine Reduktion des IOP von $17 \mathrm{mmHg}$ präoperativ auf $16 \mathrm{mmHg}$ bei dem einen Patienten und von $20 \mathrm{mmHg}$ auf $13 \mathrm{mmHg}$ bei dem anderen 
Patienten. Die mittlere Zahl an Glaukommedikamenten wurde von 2,4 präoperativ auf 0,25 bei der letzten Vorstellung im Rahmen der Nachbeobachtung reduziert. Es wurde eine Komplikation verzeichnet, die aus einer begrenzten Descemetolyse limbusnah bestand, die durch Austritt von Viskoelastikum aus dem Schlemm-Kanal während der Dilatation entstand. Komplikationen durch die Anwendung des iTrack wurden nicht beschrieben.

Schlussfolgerungen ABiC konnte bei dieser Gruppe von Patienten ohne Probleme mit minimalen Komplikationen durchgeführt werden. Obwohl die initialen Ergebnisse dieser Studie zeigen, dass ABiC den IOP und die Medikation vergleichbar mit der konventionellen Kanaloplastik senkt, bedarf es einer länger dauernden Untersuchung bei einer größeren Patientengruppe, um die Effizienz dieser minimalinvasiven Glaukomoperation $\mathrm{zu}$ belegen.

Schlüsselwörter Kanaloplastik $\cdot \mathrm{ABiC} \cdot$ Kombinierte Operation · POAG

\section{Introduction}

Primary open-angle glaucoma (POAG) is a sightthreatening disorder caused by inadequate ocular outflow, leading to elevated intraocular pressure (IOP).

There are a number of surgical treatment options for POAG. Traditionally, these have included aqueous shunts and trabeculectomy, which, although effective, are associated with numerous side effects including bleb leaks, cataracts, blebitis, endophthalmitis, and vision loss [1-3].

Perhaps not surprisingly, glaucoma surgeons are increasingly turning to non-penetrating and/or blebindependent procedures such as the Trabectome ${ }^{\circledR}$, the iStent ${ }^{\circledR}$, and an investigational device known as the Hydrus Microstent ${ }^{\mathrm{TM}}$. However, while safer than conventional glaucoma surgery, these minimally invasive glaucoma surgery (MIGS) options are usually performed alongside cataract surgery to confer maximum benefit but appear to be less effective, with patients often requiring medical therapy to maintain their IOP [4-6]. This is likely explained by the fact that each of these approaches fails to address all aspects of the ocular outflow system [7, 8]. By contrast, canaloplasty, a minimally invasive glaucoma treatment that addresses all aspects of the ocular outflow system, i. e., the trabecular meshwork, Schlemm's canal, and the distal collector channels, is not only safe, but has also been shown to be as effective as filtering surgery both in terms of IOP-lowering effects and reducing dependence on glaucoma medication [9, 10]. Canaloplasty is also effective with or without cataract surgery [11-13].

An evolution of viscocanalostomy, traditional canaloplasty employs circumferential $\left(360^{\circ}\right)$ catheterization of Schlemm's canal along with gentle viscodilation. This breaks adhesions within the canal and allows the compressed tissue planes of the trabecular meshwork and sclera to separate and any herniated trabecular meshwork tissue to withdraw from collector channels. Traditional canaloplasty employs placement of a 90 or 10-0 Prolene tensioning suture/stent to ensure the patency of Schlemm's canal. However, a review of 3-year data by Lewis and colleagues indicated that $360^{\circ}$ viscodilation alone, i.e., canaloplasty without a suture, successfully lowered IOP [11]. A study by Susan Senft, MD, also showed that the presence or absence of a suture did not affect outcomes such as visual acuity, IOP, visual field parameters, and number of medications required to maintain IOP [14].

Approved by the United States Food and Drug Administration, suture-free canaloplasty, known as ab interno canaloplasty ( $\mathrm{ABiC})$, is gaining popularity with glaucoma surgeons across Europe and the United States as a treatment for mild-to-moderate POAG, mainly thanks to its ease of use, comprehensive approach, and low risk profile. ABiC also spares conjunctival manipulation, which means that future procedures can be performed if necessary [15] and is the only MIGS to address all aspects of ocular outflow.

Since ABiC is a relatively new development of traditional canaloplasty, as yet there are no published studies describing the procedure and few data describing clinical outcomes. The aim of this case series study, therefore, was twofold: to describe and evaluate the surgical procedure, and to assess the ability of $\mathrm{ABiC}$ to lower IOP and reduce dependence on medication in patients with POAG.

\section{Methods}

\section{Study design and patients}

This was a single-center consecutive case series study designed to evaluate the efficacy of $\mathrm{ABiC}$ in reducing IOP and dependence on glaucoma medication at 1, 3, 6,9 , and 12 months postoperatively. Secondary endpoints included surgical and postsurgical complications. All surgeries were undertaken at Augencentrum Köln-Porz and performed by a single surgeon (NK).

The study was performed in accordance with the principles stated in the Declaration of Helsinki and its amendments, and all patients provided written informed consent.

Inclusion criteria were a minimum age of 18 years, cataract or pseudophakia, and a diagnosis of controlled POAG or exfoliative glaucoma. Phakic patients and those with neovascular disease, uveitis, peripheral anterior synechiae, as well as angle-closure, narrowangle, neovascular, posttraumatic, and other forms of secondary glaucomas were not eligible for inclusion in the study. 


\section{Clinical examinations}

Ophthalmic examinations including medication use, IOP, slit-lamp, and fundus examination were performed at baseline and at 1 day, 1, 3, 6, 9, and 12 months postoperatively. Gonioscopy was performed at baseline, 1, 3, 6, 9, and 12 months. A complete medical history was also taken before patients underwent the procedure.

\section{Surgical procedure}

All patients underwent $\mathrm{ABiC}$ under local anesthesia consisting of retrobulbar injection of Carbocaine and Lidocaine. The iTrack ${ }^{\mathrm{TM}} 250-\mu \mathrm{m}$ microcatheter (Ellex Medical Lasers Pty Ltd., Adelaide, Australia) with a fiber-optic light and lumen was passed through a clear corneal incision $(1.8 \mathrm{~mm}$ in pseudophakic eyes and $2.4 \mathrm{~mm}$ in combined cases) and then through a small opening in the trabecular meshwork in order to circumferentially viscodilate and intubate Schlemm's canal (Fig. 1). The meshwork opening was made by utilizing a $24-\mathrm{G}$ needle with a $20^{\circ}$ bent tip (Fig. 2). Precisely controlled delivery of Healon/ Healon GV during advancement and withdrawal of the catheter allowed the compressed tissue planes of the trabecular meshwork to separate, and any herni-

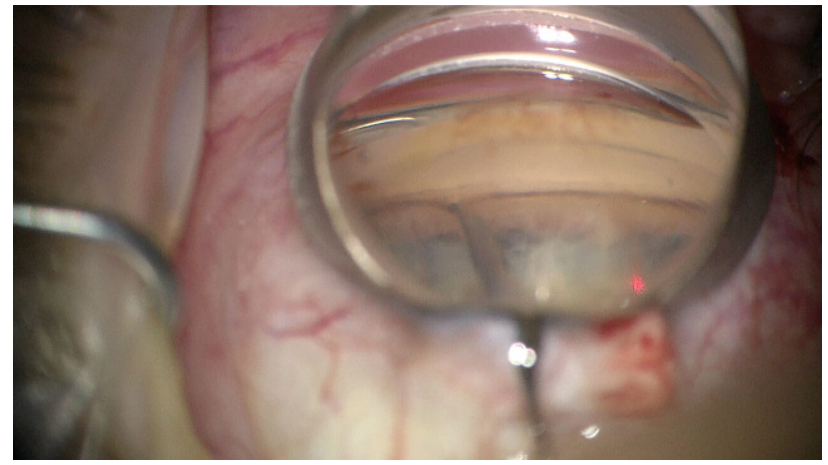

Fig. 1 Catheter tip introduced into Schlemm's canal. Tip location visible by red light shining through the trabecular meshwork

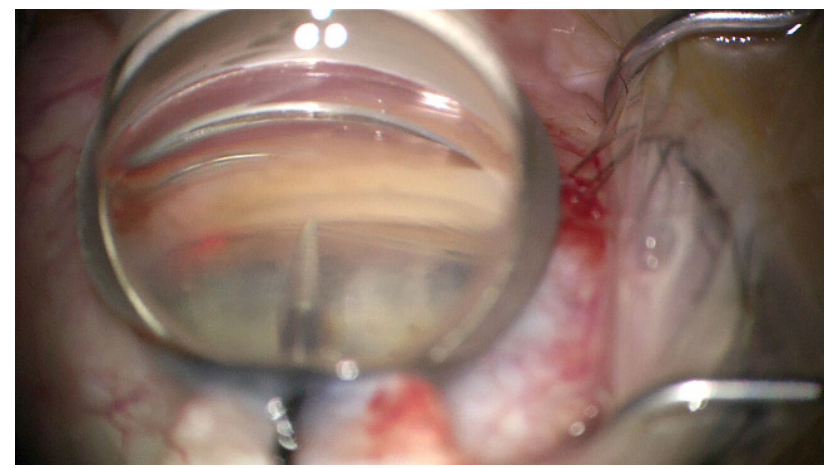

Fig. 2 A 24-G needle in location for the incision of the trabecular meshwork. Incision location: transit from pigmented to nonpigmented meshwork ated inner wall tissue to withdraw from the collector channels. In combined cases, phacoemulsification and IOL implantation were performed prior to $\mathrm{ABiC}$. At the end of the procedure, Healon was removed from the anterior chamber and the pupil was constricted using a small dose of Miochol. A subconjunctival dose of gentamycin and dexamethasone was then applied.

Postoperatively, patients received combined drops of gentamycin and dexamethasone four times daily for 1 week followed by diclofenac drops four times daily for 1 month.

\section{Results}

In total, 20 eyes (11 OS, 9 OD) of 20 patients (mean age, $76 \pm 5.79$ years; 10 male: 7 female) were enrolled in the study.

Preoperatively, mean IOP (all eyes) was $18.5 \pm$ $3.44 \mathrm{mmHg}$. Mean IOP at 1, 3, 6, and 9 months was $14.88 \pm 2.82 \mathrm{mmHg}(n=17), 13.80 \pm 2.05(n=12)$, $14.57 \pm 2.59 \mathrm{mmHg}(n=9)$, and $15.47 \pm 2.42(n=6)$, respectively (Table 1). These data correspond to reductions in IOP of $19.57 \%, 25.41 \%, 21.25 \%$, and $16.38 \%$ at $1,3,6$, and 9 months postoperatively. Additionally, 12-month data for two patients showed that IOP had reduced from $17 \mathrm{~mm} \mathrm{Hg}$ preoperatively to $16 \mathrm{~mm} \mathrm{Hg}$ in one patient and from 20 to $13 \mathrm{~mm} \mathrm{Hg}$ in the other patient.

A reduction in dependence on antiglaucoma medications was also noted. Preoperatively, all patients required at least one medication, with four of 20 (20\%) patients requiring three medications to control their IOP. At the last follow-up visit, only four of 20 (20\%) patients still required antiglaucoma medication (one medication each) versus $100 \%$ of patients preoperatively (Table 2). Overall, considering the number of drops administered combined with the number of different medications used, mean medication use reduced from 2.4 preoperatively to 0.25 at the last followup visit.

There was one complication, i.e., limited descemetolysis near the limbus by the viscoelastic during the dilatation of Schlemm's canal. No adverse events as a result of the iTrack $^{\mathrm{TM}}$ device were reported.

Table 1 Reductions in mean IOP

\begin{tabular}{|l|l|l|}
\hline Examination & $n$ & Mean IOP $(\mathrm{mm} \mathrm{Hg}) \pm S D$ \\
\hline Preoperative & 20 & $18.5 \pm 3.44$ \\
\hline 1 Month & 17 & $14.88 \pm 2.82$ \\
\hline 3 Months & 12 & $13.80 \pm 2.05$ \\
\hline 6 Months & 9 & $14.57 \pm 2.59$ \\
\hline 9 Months & 6 & $15.47 \pm 2.42$ \\
\hline 12 Months & 2 & $14 \pm 2.12$ \\
\hline IOP intraocular pressure, & SD standard deviation \\
\hline
\end{tabular}


Table 2 Reduction in medication use

\begin{tabular}{|l|l|l|}
\hline Eye & Preoperative medication $(n)$ & Postoperative medication $(n)$ \\
\hline 1 & 1 & 1 \\
\hline 2 & 1 & 0 \\
\hline 3 & 3 & 1 \\
\hline 4 & 2 & 0 \\
\hline 5 & 3 & 0 \\
\hline 6 & 1 & 0 \\
\hline 7 & 1 & 0 \\
\hline 8 & 2 & 0 \\
\hline 9 & 1 & 0 \\
\hline 10 & 3 & 0 \\
\hline 11 & 2 & 0 \\
\hline 12 & 3 & 0 \\
\hline 13 & 1 & 0 \\
\hline 14 & 1 & 1 \\
\hline 15 & 1 & 0 \\
\hline 16 & 1 & 0 \\
\hline 17 & 1 & 1 \\
\hline 18 & 1 & 0 \\
\hline 19 & 1 & 0 \\
\hline 20 & 2 & 0 \\
\hline$n$ number of medications & \\
\hline
\end{tabular}

\section{Discussion}

Although trabeculectomy and aqueous tube shunts are still the mainstays of glaucoma treatment with their efficiency in terms of IOP reduction compared with canaloplasty [16-19], there appears to be a growing interest in bleb-free, minimally invasive procedures that offer a better safety profile. However, MIGS such as the Trabectome ${ }^{\circledR}$ and the iStent ${ }^{\circledR}$ are not always effective, particularly when performed as standalone procedures [4-6]. By contrast, a number of peer-reviewed studies show that canaloplasty is not only minimally invasive, but also maximally effective. $\mathrm{ABiC}$ works in the same way as traditional canaloplasty, but does not employ a tensioning suture; thus, it may be considered as angioplasty without a stent. $\mathrm{ABiC}$ also differs from traditional canaloplasty in that the iTRACK ${ }^{\mathrm{TM}}$ microcatheter is inserted through either a clear corneal or a limbal micro-incision, and requires the creation of a scleral flap.

Since $\mathrm{ABiC}$ is a relatively new development of traditional Canaloplasty, there are few published data describing its IOP-lowering effects or its ability to reduce dependence on medications. In this case series study, there were reductions in IOP of between 16.38 and $25.41 \%$ through 9 months postoperatively. Additionally, we found that dependence on medication was significantly reduced; at the last follow-up visit, only $20 \%$ of patients still required medication, versus $100 \%$ before the procedure.

It somewhat challenging to compare these findings with those of other studies, since there are few published data describing outcomes following ABiC. However, results from Lewis and coworkers' landmark study of Canaloplasty showed that mean postoperative IOP for all eyes $(n=157)$ decreased from $23.8 \pm 5.0 \mathrm{mmHg}$ on $1.8 \pm 0.9$ medications preoperatively to $15.2 \pm 3.5 \mathrm{~mm} \mathrm{Hg}$ on $0.8 \pm 0.9$ medications at 3 years postoperatively. Of these patients, approximately $15 \%$ did not receive a tensioning suture [11]. Additionally, data from an ongoing case series study by Mark J. Gallardo, MD, and Mahmoud A. Khaimi, MD, who evaluated $\mathrm{ABiC}$ with and without phacoemulsification showed that for all eyes $(n=228)$ there was a marked reduction in mean IOP $(27.9 \%)$ and number of medications (50\%) at 6 months postoperatively $(n=52)$. A subanalysis showed that in eyes receiving $\mathrm{ABiC}$ combined with cataract surgery $(n=127)$, there was a $23.52 \%$ reduction in mean IOP and a $100 \%$ reduction in number of medications at the 6 -month visit $(n=34)$. When $\mathrm{ABiC}$ was performed as a standalone procedure in pseudophakic patients, data from Dr. Khaimi's and Dr. Gallardo's studies combined $(n=83)$ showed there was a total average decrease of $33.48 \%$ in mean IOP and $66.66 \%$ in mean medication use at 6 months postoperatively $(n=18$; [20]). Our own findings are on a par with these data, suggesting that $\mathrm{ABiC}$ produces consistent outcomes and does not need to be performed alongside cataract surgery in order to be effective. The present findings are also in line with outcomes following traditional canaloplasty, which show that IOP is consistently lowered to the mid-teens [9, 21, 22].

The second aim of the present study was to evaluate the surgical procedure and to assess the nature and incidence of complications. In the present study, there was only one complication-limited descemetolysis near the limbus by the viscoelastic during the dilatation of Schlemm's canal. Although there were no cases of hyphema in the present study, surgeons should be aware that this may occur following canaloplasty/ABiC. While some surgeons may be concerned about this, it is actually a positive sign, confirming that there is connection between the anterior chamber and the aqueous into the outflow system [23, 24]. Surgeons may also find that, on occasion, they encounter a collapsed Schlemm's canal. Occasionally (about $5 \%$ of the cases), the catheter trails off into a collector channel. However, this is easily overcome. Because the iTRACK-250 ${ }^{\mathrm{TM}}$ microcatheter is so long, the surgeon is able to make a paracentesis $180^{\circ}$ away and start to catheterize in the opposite direction. Doing so should lead to successful $360^{\circ}$ viscodilation. There may also be rare occasions where the catheter is misdirected, for example, it may go into the suprachoroidal space. However, the tip is blunt so there is no risk of damage to the choroid. The illuminated tip also advises of the catheter's location. Catheter misdirection may be resolved by applying pressure to the affected area or, again, by making a paracentesis $180^{\circ}$ away from 
the site of the misdirection and catheterizing in the opposite direction.

Surgeons new to canaloplasty/ABiC may be somewhat nervous about the technique, particularly those who have never performed viscocanalostomy. One of the main challenges with traditional canaloplasty was placing a tensioning suture, an issue negated by ABiC. There is no doubt that both traditional canaloplasty and $\mathrm{ABiC}$ have a learning curve, but, typically, a surgical fellow is comfortable with $\mathrm{ABiC}$ after only five to ten procedures. An experienced glaucoma surgeon may achieve familiarity with the procedure much sooner. Moreover, making the transition to $\mathrm{ABiC}$ is easier now than it was when it was first introduced 10 years ago; since that time, we have become more familiar with the procedure and a certain consensus has emerged about the best way to achieve consistently excellent results with canaloplasty or ABiC.

Clearly, the present study has limitations including the small study cohort. Additionally, follow-up data beyond 6 months postoperative were only available for a handful of patients.

However, findings from this small study indicate that $\mathrm{ABiC}$ lowers IOP and medication dependency comparable to conventional canaloplasty and other studies describing outcomes following $\mathrm{ABiC}$. The procedure was also straightforward to perform in this group of patients, with minimal complications. Nevertheless, long-term follow-up in a large patient cohort is required to confirm the efficacy of this minimally invasive glaucoma procedure.

Conflict of interest N. Körber declares that he has no competing interests.

Open Access This article is distributed under the terms of the Creative Commons Attribution 4.0 International License (http://creativecommons.org/licenses/by/4.0/), which permits unrestricted use, distribution, and reproduction in any medium, provided you give appropriate credit to the original author(s) and the source, provide a link to the Creative Commons license, and indicate if changes were made.

\section{References}

1. Zahid S, Musch DC, Niziol LM, et al. Risk of endophthalmitis and other long-term complications of trabeculectomy in the Collaborative Initial Glaucoma Treatment Study (CIGTS). Am JOphthalmol. 2013;155(4):674-80.

2. Mac I, Soltau JB. Glaucoma-filtering bleb infections. Curr Opin Ophthalmol. 2003;14(2):91-4.

3. DeBryPW, Perkins TW, HeatleyG, etal. Incidence oflate-onset bleb-related complications following trabeculectomy with mitomycin. Arch Ophthalmol. 2002;120:297-300.

4. FDA. Executive summary prepared for the July 30, 2010 meeting of the Ophthalmic Devices Panel: P080030 Glaukos, Inc. iStent Trabecular Micro-Bypass Stent Model GTS-100 R/L. 2014.

5. Camras LJ, Yuan F, Fan S, et al. A novel Schlemm's Canal scaffold increases outflow facility in a human anterior segment perfusion model. Invest Ophthalmol Vis Sci. 2012;53(10):6115-21.

6. Saheb H, Ahmed IIK. Micro-invasive glaucoma surgery: current perspectives and future directions. Curr Opin Ophthalmol.2012;23(2):96-104.

7. BrandãoLM, Grieshaber MC. Update on minimallyinvasive glaucoma surgery (MIGS) and newimplants. JOphthalmol. 2013;705915. https://doi.org/10.1155/2013/705915.

8. Nichamin LD. Glaukos iStent Trabecular Micro-Bypass. Middle East Afr J Ophthalmol. 2009;16(3):138-40.

9. Brüggemann A, Despouy JT, Wegent A, et al. Intraindividual comparison of Canaloplasty versus trabeculectomy with mitomycin $\mathrm{C}$ in a single-surgeon series. J Glaucoma. 2013;22(7):577-83.

10. Klink T, Sauer J, Körber NJ, et al. Quality of life following glaucoma surgery: canaloplasty versus trabeculectomy. Clin Ophthalmol. 2014;18(9):7-16.

11. Lewis RA, von Wolff K, Tetz M, et al. Canaloplasty: threeyear results of circumferential viscodilation and tensioning of Schlemm's canal using a microcatheter to treat open-angle glaucoma. Graefes Arch Clin Exp Ophthalmol. 2011;249(10):1537-45.

12. Tetz M, Koerber N, Shingleton BJ, etal. Phacoemulsification and intraocular lens implantation before, during, or after canaloplasty in eyes with open-angle glaucoma: 3-year results. J Glaucoma. 2015;24:187-94

13. Lopes-Cardoso I, Esteves F, Amorim M, et al. Circumferential viscocanalostomy with suture tensioning in Schlemm canal (canaloplasty) - one-year experience. Arch Soc Esp Oftalmol. 2013;88(6):207-15.

14. Senft SH. Canaloplasty after failed glaucoma surgeries. Presented at the World Ophthalmology Congress 2014.

15. Khaimi MA. Canaloplasty: a minimally invasive and maximally effective glaucoma treatment. J Ophthalmol. 2015;2015:485065.

16. Matlach J, Dhillon C, Hain J, et al. Trabeculectomy versus canaloplasty (TVC study) in the treatment of patients with open-angle glaucoma: a prospective randomized clinical trial. Acta Ophthalmol. 2015;93(8):753-61.

17. Garris WJ, Le C, Zurakowski D, Ayyala RS. Comparison of surgical outcomes between canaloplasty and trabeculectomy with mitomycin $\mathrm{C}$ at 2-year follow-up: a longitudinal cohort study. Indian J Ophthalmol. 2018;66(1):66-70.

18. Ayyala RS, Chaudhry AL, Okogbaa CB, Zurakowski D. Comparison of surgical outcomes between canaloplasty and trabeculectomy at 12 months' follow-up. Opthalmology. 2011;118(12):2427-33.

19. Brüggemann A, Despouy JT, Wegent A, Müller M. Intraindividual comparison of Canaloplasty versus trabeculectomy with mitomycin $\mathrm{C}$ in a single-surgeon series. J Glaucoma. 2013;22(7):577-83.

20. Gallardo MJ, Khaimi MA. Presented at the American Academy of Ophthalmology 2015. 2015. Las Vegas

21 . Koerber NJ. Canaloplasty in one eye compared with viscocanalostomy in the contralateral eye in patients with bilateral open-angle glaucoma. J Glaucoma. 2012;21(2):129-34.

22. Bull H, von Wolff K, Körber N, et al. Three-year canaloplasty outcomes for the treatment of open-angle glaucoma: European study results. Graefes Arch Clin Exp Ophthalmol. 2011;249(10):1537-45.

23. Grieshaber MC, Schoetzau A, Flammer J, Orgül S. Postoperative microhyphema as a positive prognostic indicator in canaloplasty. Acta Ophthalmol. 2013;91(2):151-6.

24. Koch JM, Heiligenhaus A, Heinz C. Canaloplasty and transient anterior chamber haemorrhage: a prognostic factor? Klin Monbl Augenheilkd. 2011;228(5):465-7. 